\title{
The Eclosion of Forest and Tree Health Stakeholdership
}

\section{Norman Dandy (corresponding author)}

Sir William Roberts Centre for Sustainable Land Use

Bangor University

Bangor

Gwynedd

$L L 572 D G$

n.dandy@bangor.ac.uk

Emily F. Porth

School of Chemistry

Joseph Black Building

University of Edinburgh

EH9 3FJ

\begin{abstract}
The anthropogenic environmental change characteristic of the Anthropocene generates numerous threats and opportunities for the non-human beings who are intrinsic to forest and tree health. There are profound consequences for both humans and non-humans as a result of natural ecosystem disturbances, such as forest fires or invasive insects, and their accompanying environmental management responses. However, the consequences for nonhumans as a result of either disturbance or management receive virtually no attention within environmental policy and practice. In this paper we argue for the growth and transformation the 'eclosion' - of the 'stakeholder' concept so as to provide a pragmatic basis for greater attentiveness to, and comprehension of, non-human interest. We explore the implications and feasibility of this, describing particular approaches to stakeholder analysis and representation that emanate from research methods including multispecies ethnography and studies in 'new
\end{abstract}


animism', that can effectively enable non-human 'voices' to be heard and taken more seriously. We conclude there are solid methodological and conceptual foundations on which to build an effective understanding of non-human stakeholdership, particularly in the area of forest and tree health.

\section{Introduction: Forest health, biological 'invasion' and non-humans}

In many forests the 'natural' disturbance caused by fire, storms, insects, and diseases is a vital component of ecosystem dynamics, playing a crucial role in ecological regeneration, succession, and overall forest health (Perry et al., 2008; Castello and Teale, 2011). Excessive or irregular disturbances, however, can significantly interfere with relationships between people and trees and the flow of benefits from forests to human society. Consequently, environmental managers often make substantial efforts to prevent major disturbances in forests, such as through controlling fire, seeking to limit pests and diseases, and designing plantation forests to withstand storms. Critically, these disturbances and our management responses to them also profoundly affect huge numbers of non-human beings. Whilst this is slowly beginning to be recognised and noted, such as in media coverage of the impact on wildlife of the 2019 Australian bushfires (e.g. SBS News, 2020), the direct consideration of the consequences for these 'others' is almost entirely absent from forest management, policy and research. Despite some notable exceptions, such as within the Te Tira Whakamātaki Māori Biosecurity Network ${ }^{1}$, non-humans are generally only considered within environmental policy in terms of their value to humans. In this paper we propose a reoriented approach that 'listens' attentively to those non-humans whose 'voices' are being systematically ignored.

We focus on forest and tree health in relation to the biological 'threats' to forest species posed by insects and pathogens, which often emanate from distant environments and are thus 'alien' to the ecosystems they are introduced to. This so-called 'biological invasion' is

\footnotetext{
${ }^{1}$ https://ttw.co.nz/
} 
considered to be one of the key threats to forests and other ecosystems in that it is a primary driving force of unwanted disturbance (Mack et al., 2010). This has led concerned forest managers, policy-makers and others to attempt to secure forest boundaries from 'alien' invertebrates and diseases so as to avoid or minimise the loss of benefits to humans, and to promote the interests of some highly valued non-human (e.g. 'native') species. Despite this, introductions of insects and diseases to 'new' environments are common (Webber, 2010) and can be particularly damaging to trees they have not co-evolved with and who, hence, have little resistance to them (Brasier, 2008).

Arguably, biological invasions and, alongside them, biosecurity policy and practice should be considered key features of the Anthropocene (Potter and Urquhart, 2017). This suggested new geological period wherein humans are the dominant force in the biosphere has seen the development of new technologies and practices, including the international plant trade and the forestry-horticulture industry, which have dramatically extended human activities across ecological and geographical boundaries (Brasier, 2008; Roques, 2010). Invertebrates and pathogens who affect trees have always spread of their own accord and, undoubtedly, humans have always incidentally spread these beings through their own activities. The spread of pests and diseases, per se, cannot therefore be considered intrinsic to the Anthropocene. However, major biological 'invasions' are inextricably linked to human movements and activities including trade, environmental management, agriculture, migration, climate change - that have undergone exponential growth, innovation and change during this period. It is, therefore, the extraordinary proliferation of invasions and associated human responses around the world that can be considered unique to the Anthropocene. It is thus surprising that biological invasions in the form of species introductions have only rarely been considered within literature on the Anthropocene (e.g., Frawley and McCalman 2014; Potter and Urquhart 2017).

As a concept, the Anthropocene highlights the structural impacts of humans on non-humans and on the Earth more broadly. However, it does little to disentangle different intra-human impacts on the biosphere, leaving in its wake the notion that, as Rutherford (2018: 208) puts it, "an undifferentiated Anthropos has ravaged the wild". This can obscure alternative narratives that emphasise the role that power imbalances between humans, such as 
colonialism, have had in environmental degradation and responses to it. In the context of forest health, for example, Lambert et al (2018: 109) note the impact of colonialism on Māori communities in Aotearoa New Zealand via the introduction and subsequent management of Kauri Dieback. Māori explicitly identify the insertion of Indigenous knowledge into policy processes as 'part of the resistance to colonisation', demonstrating how other worldviews have long been excluded in regard to biosecurity and forest health in the Anthropocene.

This paper considers the status of non-human beings as stakeholders in contemporary forest health policy. It asserts that there is a pressing need to de-centre humans in an era defined by keeping the lives and histories of humans exclusively front and centre (Human Animal Research Network Editorial Collective 2015). We begin by briefly restating the varied and multiple motives for considering non-human stakeholders at this time, identifying in particular the theoretical approaches to environmental studies that de-centre humans. We also describe how contemporary human practices generate both opportunities and threats for nonhumans in the context of tree and forest health, and then explore the prospect of using stakeholdership as a conceptual and pragmatic space to account for non-humans within policy processes. In the second half of the paper we go on to describe some of the stakeholderoriented methodological innovations from fields including human-animal studies, ecofeminism, multispecies ethnography, and animist research. These methods are important as a way to enable those involved in tree health policy and practice to 'listen' more attentively to non-humans and understand their stakes.

\section{Non-human life in the forest: Status, opportunities and threats}

It can be argued that the West's history of defining non-human beings as objects and as Others, who can be both casually and systematically exploited for human benefit, is the root cause of current and historical environmental crises. Many green philosophers have focused on de-centring humans and asserting ecocentric, biocentric and/or ecofeminist positions. Within this there have been varied discussions on human ethical obligations to a few specific non-human beings associated with forests, including 'pest' species. Draney (1997), for example, reviewed the potential implications of attributing rights to insect pests. He 
concluded that whilst the moral significance of individual organisms would be 'infinitesimally small', ethical obligations may emerge at scale, where the continued survival of a pest species was at risk or where human rights may be threatened through ecological damage. More recently, Dandy et al., (2018) considered how applying alternative ethical frameworks to an invasive insect 'outbreak' could impact the management of that outbreak. They concluded that whilst many management methods may remain broadly unchanged, there would be a clear need for vastly increased preparation and inspection prior to management action, which is in tension with the dominant 'emergency modality' approach to outbreak management.

A number of contemporary human activities create distinct and novel opportunities for the non-humans associated with forests: trees, invertebrates, pathogens, and many other flora and fauna. A prominent example of these activities is the ongoing creation of monoculture forests for more than a century. These plantation forests, which are often created using non-native tree species, further the interests of those species by expanding their population and range. Sitka spruce (Picea sitchensis) is perhaps the best example of this, having extended its range from the Pacific northwest of North America to Northern Europe, and most notably into Britain. Eucalyptus species, native to Australia and surrounding islands, have fared even better, spreading their range to every continent where they are planted for a wide range of uses. These intentionally planted monoculture forests may themselves be understood as human-managed biological invasions.

The establishment of monoculture forests creates multiple opportunities for the invertebrates and pathogens associated with them to move and expand their populations and range. Clearly, without these 'host' forests, closely dependent invertebrates and pathogens could not move, and the establishment of these forests as even-aged monocultures makes them particularly conducive as hosts both for 'invasive' species, and some native species. For instance, in the case of the latter, the Asian longhorn beetle (Anaplophora glabripennis, ALB) only became a 'problem species' in China, its native territory, when foresters began to plant monoculture forests of ALB's favoured tree species (Haack et al., 2010, p. 527). At that point, ALB began to expand and the large increase in population density resulted in their unintended introduction to the wood packaging and horticulture industry supply chains. In this case, both 
monoculture forestry and trade created opportunities for previously restricted insects to radically expand their population and range at both a regional and global scale.

Climate change is also arguably creating environments convivial to some pests and diseases. Many insect species are effectively controlled by the weather; cold winter weather will not only reduce their population, but it also ensures that they have a restricted range. This has become problematic in some parts of the world where insect species that were formerly controlled by cold weather have now spread far beyond their normal range due to the warming climate. This has resulted in the widespread destruction of forests in places like Canada's Pacific Northwest where mountain pine beetles (Dendroctonus ponderosae, MPB), a native insect species, has radically extended its territory south (Carroll et al. 2003).

Alongside the unique opportunities afforded to non-humans in the Anthropocene, there also sit a number of novel threats generated by contemporary human activities. Perhaps chief amongst these in relation to forest health are the socio-technical innovations of contemporary biosecurity practice. New pesticides, 'sanitation' felling techniques, close surveillance, and eradication regimes can all impact directly upon the wellbeing and flourishing of non-human beings, whether they are categorised as 'pests' or as infected / infested 'hosts'. 'Host' trees are cut down and incinerated, usually with little specific assessment of the extent of infection / infestation, nor the potential for long term survival. 'Pests' are intentionally killed in numbers far in excess of 'natural' death rates.

Beyond these foreseeable impacts on 'pests' and 'hosts', there is the potential for significant collateral harm to 'non-target' non-humans intrinsic to biosecurity practices. For example, the use of pesticides against invasive moth species, such as oak processionary moth (Thaumetopoea processionea), have substantial collateral impacts on other Lepidoptera. Further, current management protocols for dealing with some tree pests (e.g. Asian longhorn beetle) demand the destruction of a wide variety of potential host trees of numerous species. Looking even further beyond non-humans who are directly threatened by biosecurity, there are still others (e.g. forests, rivers, and glaciers) who can be impacted by these practices if conducted at a large enough scale. Obligations towards these 'beings' or 'persons' are being increasingly formalised into legal 'rights' frameworks that need to be accounted for in 
environmental policy and management decision-making (e.g. Davidson 2017). Although not unproblematic (O’Donnell 2017), in time, legal 'rights' for non-humans may lead to a closer alignment of Western and Indigenous perspectives and lead to epistemological change in policy.

Contemporary biosecurity practice not only creates direct threats to non-humans ('pests') but, of course, also presents opportunities for the non-humans who are deliberately protected through these practices (usually due to their instrumental value to humans). Many of these non-humans are classified as 'native' and thus of interest to conservation. 'Pest' control in forests is generally justified through the protection of existing, and particularly 'indigenous', species. Although indigenous species like MPB can become problematic, it is 'alien' and 'invasive' species that are perceived to be the primary threat to 'native' ecosystems and species by multiple global institutions, including IUCN (www.issg.org), the Convention on Biological Diversity (www.cbd.int/invasive), and FAO (www.fao.org/forestry/aliens). To this end, FAO (2016) defines a pest as 'any species, strain or biotype of plant, animal or pathogenic agent injurious to plants or plant products'. This narrative is echoed at international, national, and local levels. For example, Defra (UK Department of Environment, Food \& Rural Affairs) notes the threat of plant 'pests' 'spreading through gardens and woodlands and potentially causing serious damage to either our native flora or commercial crops'(2011, p. 4). Clearly, the interests of some particular non-humans are already at the centre of forest health policy and practice, albeit for primarily anthropocentric reasons. The criteria for selecting which non-humans are within the circle of consideration are both problematic and blurred (Buller 2013).

\section{The eclosion of forest and tree health stakeholdership}

How can these threats and opportunities be captured, understood, and recognised within contemporary forest health policy? Is it possible for a new framework of forest health management to emerge which accounts for non-humans in ethical terms more appropriate to the Anthropocene, and which is also meaningful for policy makers and others involved in forest health? To frame this goal, our paper borrows the concept of eclosion from the 
entomological canon: the act of emergence of an adult insect from its pupal case. Eclosion encompasses notions of growth, profound change, and transformation, yet it is also a tangible biological reference to the human stakeholders who arguably need to adopt a new approach to forest and tree health in the face of the current climate crisis. In this section we argue that the well-established concept of stakeholdership provides an appropriate framework through which to achieve this transformation.

A (human) stakeholder is most commonly defined as an individual, organisation, or other social group that can affect (influence) and/or be affected by (have an interest in) a phenomenon such as a new commercial product, new government policy, or event (Freeman, 1984). Although there are often clear normative drivers for stakeholder analysis and engagement, these processes are normally undertaken primarily for instrumental reasons such as the reduction of conflict or removal of obstacles to (business or policy) success (Reed et al 2009). Within forest policy, stakeholders have most commonly been conceptualised as those individuals and groups with strong and direct links to trees, woodlands, and forests. At the core of these are those actors involved in the forest industry (e.g. landowners, timber companies, arboriculturalists, etc.), although in recent decades it has grown to encompass the communities living in and around wooded areas. Stakeholder analysis is now a feature of many woodland planning and management standards. Such analysis only rarely, however, acknowledges the stakes held by human actors less directly connected to forestry (e.g. conservation organisations, educational institutions) and never explicitly extends to conceptualising non-humans as forest policy stakeholders.

In relation to forest health, recent work (Dandy et al. 2017) has begun to map the broad human stakeholder landscape and developed a series of categorisations to rationalise this. Categories of influence (that is, actors with the capacity to affect forest health outcomes) include 'vectors' (whose activities physically spread a pest or disease), 'governors' (able to set rules and regulations around forest health), 'managers' (possess the technical skills and capabilities required to address pests and diseases), 'monitors' (with knowledge required to predict, detect, identify, or otherwise understand forest health), and 'networkers' (who are key to communication amongst stakeholders). Categories of interest (that is, actors who are affected by forest health issues) can be divided into those who are affected negatively or 
positively. They include 'value losers' (for whom pest or disease outbreaks reduce the value of trees or land), 'cost losers' (who must pay the economic costs of management), and 'collateral losers' (who are negatively affected by a loss in non-tree related value, such as reputational loss) as stakeholders who can be affected negatively. 'Outcome winners' are those for whom outbreaks bring benefits (e.g. economic income for management) and 'contributors', those who are engaged in activities that are beneficial to them, but which are implicated in the occurrence of outbreaks. It is important to note that stake is particularly dependent on context and can change over time in regard to space, scale, and influence.

\section{Non-human Stakeholders}

Beginning with Mark Starik (1995), there is a distinct movement that seeks to bring nonhumans into the realm of stakeholder analysis and management. This sows the seeds for the eclosion, or transformation, of forest health stakeholdership. The starting point for this was recognising the dependence of business on the natural environment, which required managers to understand their firm's relationship with its environment (Starik, 1995). For the forestryhorticultural industry, this dependence is immediate and clear, and therefore the possibility of treating (some) non-humans as stakeholders is reasonably obvious for purely instrumental reasons such as crop damage limitation. The argument can, however, proceed far beyond such an anthropocentric starting point (Driscoll and Starik, 2004) to recognise a deeper interdependence between non-humans and humans, and (normatively) to consider nonhumans as political entities with interests, a 'voice', and even rights. Such arguments for including non-human entities as stakeholders often flow from conventional positions adopting broad definitions of stake (e.g. Waddock 2011).

The majority of opposition to including non-humans as stakeholders originates in concerns that, despite the existence of moral obligations, to do so entails major definitional loss, rendering the term 'stakeholder' meaningless; it becomes almost impossible to say who does not qualify as a stakeholder (Phillips and Reichart, 2000). It is true that broadening the definition of stakeholder can make stakeholder analysis a more difficult and complex enterprise that is likely to demand a differentiated understanding of what it means to have or not have a stake. However, it is unconvincing as a reason to exclude non-humans per se, 
given the moral obligations and entanglements generated by the Anthropocene. Furthermore, if the systemic environmental problems we are facing today have been caused by a failure to consider non-humans, then stakeholder management that continues to do so is bound to fail. To date, applications of the stakeholdership concept to non-humans remain rare, although Tryggestad et al (2013) and Sage et al (2014) engaged with the concept to show how animals can become salient within construction projects. This work demonstrates the limitations of existing ways of incorporating non-humans within established processes, such as environmental impact assessment, and highlights the need for their transformation.

Non-human influence and interest in forest and tree health

Taking our lead from Starik and others, in this section we begin to eclose forest health stakeholdership by challenging the established anthropocentric conceptualisation of stake. We do this by considering the many ways that non-humans can affect and be affected by biosecurity practices. Non-humans who are intrinsic to forestry include trees and the invertebrates and other organisms who can affect them: these are the obvious beings who might be considered stakeholders. Beyond these, non-humans on the periphery of forest health include other species for whom trees and forests are home, as well as 'beings' - in animistic terms - such as rivers who can be affected by larger scale changes to forest ecosystems.

At the core of forest health policy and practice is the fact that non-human 'pests' can affect trees and forests, with consequent impacts on other species and associated human interests. Clearly, therefore, invertebrates and pathogens can influence forest health. This influence is the biological outcome of these species living out their normal life course: it is essential to their very being. In this regard, these species are key agents of change in the health of trees and forests, and thus have a strong direct stake, albeit one that is potentially mediated by numerous intervening factors such as their anthropogenic translocation and the existence of hospitable environments in new locations. To translate this, an equivalent example may be that young people are stakeholders in juvenile anti-social behaviour policy and practice, or that farmers are stakeholders in food standards policy. In all of these cases the stakeholders 
are those who, often in interaction with contextual factors and other stakeholders, are producing the phenomenon that (arguably) requires management.

Trees (and assemblages of trees) possess particular characteristics of resistance and resilience to 'pests' and thus can, in some senses, be said to influence forest health. For example, a recent study (Amo et al. 2013) demonstrated that great tits (Parus major) are drawn to caterpillar-infested trees, even when the birds cannot see the larvae or the damage caused by their feeding. Rather, the trees emit volatile chemical compounds that can be smelled by both birds and predatory insects, which are different to the chemicals emitted by healthy trees. This is mutually beneficial to both the trees and the birds, as the birds can easily find food, and trees have the help of both vertebrate and invertebrate predators to rid them of a potentially threatening Lepidoptera infestation.

Other non-humans possess capabilities associated with controlling 'pest' species and/or reducing their impacts. The most obvious examples are species that prey on 'pest' species. These can either occur naturally, such as the predation of Emerald Ash Borer (Agrilus planipennis) beetles by North American woodpeckers (Lindell et al. 2008), and/or be utilised by humans as 'biological control', as in the way humans have bred and released Rhizophagus grandis in certain areas of the UK to manage Dendroctonus micans (great spruce bark beetle) (Evans and Fielding 1994). In these ways, such beings have a considerable influence over the health of forests.

Non-humans have a range of interests in forest health that are both positive and negative. First and foremost, established trees clearly have an interest in living and remaining 'healthy'2. As already noted however, forestry and horticultural practices create numerous opportunities for certain species to flourish and expand in population and range. Some trees, especially conifers and Eucalypts, now extend well beyond their 'native' area and with this comes an expansion of habitat for the range of species associated with those tree species including the invertebrates and pathogens who are 'injurious' to them. Trade activities also present opportunities for non-humans to move, without the awareness of the humans

\footnotetext{
2 There is considerable debate regarding the definition of a 'healthy' tree given the degree of co-dependency between plants, pathogens, fungi, and other micro-organisms.
} 
involved. Anthropogenic climate change presents further opportunities for species to find new 'homes'. However, incoming species can present threats and costs to established nonhumans who can be displaced.

Biosecurity and 'outbreak' management, the core practices of forest health, generate further stakes for non-humans that are, once again, both positive and negative. Biosecurity actions, such as inspection and phytosanitary measures, are explicitly targeted at limiting the opportunities for non-human species to expand into new areas. 'Outbreak' management methods, which include 'sanitation' felling and burning, pesticide application, and biological control (predator species) are even more antipathetic to these non-humans, aimed, as they are, at killing them. These measures also often have additional negative impacts on other nonhumans. For example, sanitation felling often extends to healthy trees (which may potentially act as host to the 'pest' organism) and pesticide application can affect non-target species.

In this section we have laid out the foundations for the transformation of forest health stakeholdership by expanding its scope to include relevant non-humans. There a strong theoretical framework and impetus to achieve this emanating from prior work, and it is clearly possible to meaningfully characterise the type of stake that non-humans can have in tree and forest health through their interests and influence. In this way, a new stakeholder landscape is starting to emerge, but perhaps the most significant challenges to its full eclosion remain.

\section{Listening to non-human stakeholders in forest and tree health policy}

Having established that at least some non-humans might be meaningfully ascribed 'stakes' in forest health and environmental management, the task remains of setting out ways to recognise and analyse what these stakes are. What approaches and techniques do we need to employ in order to capture these stakes? How can we engage, communicate with, and 'listen to' non-humans so as to comprehend their interests in and influence over forest and tree health? As Romreo and Dryzek (2020) note, myriad human social structures 'disable' our 
'capacity to interpret signals from the nonhuman world'. Can we 'listen' to non-humans in a way that adequately mitigates our position as 'interpretant' (Romreo and Dryzek, 2020) and the anthropocentrism that could be an inevitable outcome of engaging with those who are so unlike humans?

At this point, is it essential to explicitly acknowledge the need for epistemological diversity in any approach to understanding the interests and influence of non-human stakeholders. The non-humans who comprise the core stakeholders in forestry (trees, pathogens, and invertebrates, most obviously) are substantively different from other non-human stakeholders that have perhaps more commonly been considered worthy of political attention. Humans find the potential for easy empathetic engagement with in charismatic megafauna (Lorimer 2010) and (not withstanding Lockwood 1987; 1988) other mammals (Regan 1981). Consequently, this means that engaging with plants, arthropods, micro-organisms, and other members of the biotic community (e.g. rivers) will require less orthodox methods of engagement, some of which we explore below. Romreo and Dryzek (2020) have begun to explore the potential for ecological communication to facilitate more inclusive forms of democracy, and any serious attempt to acknowledge the lives of and 'listen' to non-humans must transcend the usual methodological and epistemological boundaries of policy-related stakeholder analysis - a process that is deeply permeated with assumptions about the capacities of stakeholders to respond to certain stimuli, in certain ways, and produce particular forms of knowledge or 'evidence'.

An illustration of the difficulties here is manifest in any attempt to offer a revised, more inclusive, definition of stakeholder. Is 'individual, organisation or social group', as per the definition used above, adequately inclusive? Or should it be altered or expanded upon to include the term 'organism', 'being' or another term? In her exploration of her childhood experience of a birch tree, Stuckey (2010) chooses to use 'knower'. In using this term in reference to any individual stakeholder, whether human or non-human, she disrupts the human/non-human dualism and the species-specific hierarchy of sentience and knowledge that the modern Western world has historically imagined to exist between humans and other beings. 
To consider seriously the possibility of being known by a birch tree is to begin to step down from the lonely pedestal of knowing, which keeps (modern) humans at the center of every story, always superior to and removed from all other beings. [...] In examining how relationship with a tree shapes awareness and knowledge, we might find ourselves reassessing what it means to know, what counts as knowledge, and who can be recognised as a knower. We might entertain a view of Earth, and of epistemology in which humans are but one extension of Earth's many-faceted ability to know. (Stuckey 2010, p. 187)

Barrett broadens this thinking and makes the point that to actively engage in other ways of knowing requires us to leave behind 'academic structures and thought systems' (Barrett 2013a, p. 419). From this perspective, to choose to use the word 'knower', alongside or in place of 'person' or 'being', may help us to better integrate the inclusion of non-human stakeholders into our worldview and our practices of stakeholder categorisation and management. With this epistemological innovation in mind, the following section describes some of the potential options for engagement, including key conceptual foundations (such as representation, empathy and intuition), necessary approaches (such as deliberately focusing on fringe or marginal actors), and the core techniques or methods that might be used within these.

\section{Proxy Representation}

Perhaps the most immediate and straightforward way to capture non-human interests would be through proxy representation. This means there would be an institutionalised or organisational representation within established processes. Indeed, at least some non-human stakeholders identified here do have substantive proxy representation capable of impacting on policy and management processes, if not necessarily embedded within them. Trees in particular are often the focus of protective action by individuals and organisations (e.g. The Woodland Trust, UK www.woodlandtrust.org.uk; the Ancient Forest Alliance, Canada www.ancientforestalliance.org). Invertebrates are the focus of some protective lobbying and representation from organisations such as Buglife, the Xerces Society, and numerous smallscale entomological societies, although this is certainly less widespread than action related to 
trees. Consequently, it is clear that these particular non-human stakeholders are not completely without representation, and some proxies take action and lobby for policy and practice that account for non-human interests and recognises their influence. For example, there have been multiple organisations campaigning for a ban on neonicotinoid insecticides in agriculture to protect diminishing bee populations. Their aim was to protect what they perceived to be the key interests of bees (being alive, able to reproduce, and in good health) and their influence (pollinating plants that are crucial to the survival of humans and many other species).

However, proxy representation of stakeholders within policy and management processes is usually undertaken by individuals with experience of being, or living the life of, those they represent. For example, farmers' union representatives are commonly farmers or those who have experience of agriculture. Trade organisations are usually represented by individuals who have worked in the represented sector. As such, the limits of this approach for nonhuman stakeholders are relatively obvious and, indeed, Starik considered the approach inadequate in his early work (1995). Clearly, those within organisations that claim to represent non-human stakeholders cannot easily replicate this - even for mammals such as squirrels, although strategies and images that seek to bring non-human experiences to life are increasingly being employed by them (e.g. 'adoption' of specific animals of conservation interest, virtual reality, moving images, documentary filmmaking) and may ultimately be anthropomorphising.

The most significant outcome of proxy representation is how it maintains the dualism between humans and non-humans. This perceived distance between humans and other knowers results in an unavoidably anthropocentric appreciation of non-human values and perspectives. Although some individuals and organisations make explicit attempts to advocate for the intrinsic value of non-humans despite this separation, it is clear that much of the advocacy for non-humans is centred on values which are explicitly anthropocentric (and defined via anthropocentric processes such as scientific inquiry). Concepts such as 'naturalness', 'nativeness', 'rarity' and 'endangerment' may result in action, but they each derive from particular perspectives of 'nature' and its value to humans, privileging some nonhumans over others. 


\section{Radical Transactiveness}

An alternative approach to stakeholder analysis and representation that perhaps holds greater promise for including non-humans is 'radical transactiveness', or RT (Hart and Sharma 2004). RT is a structured and deliberate process for bringing-in 'fringe' stakeholders, particularly those who may be weak or are otherwise 'invisible' to policy-makers or managers.

Developed to enable businesses to manage disruptive change from non-traditional stakeholders, RT focuses on the poor, isolated, or non-salient actors who are traditionally beyond the scope of stakeholder analysis and management. It is a dynamic but systematic approach through which organisations deliberately extend the scope of their analysis ('fanout') and then attempt to identify and explore diverse views. They then integrate new and 'disconfirming' knowledge through deep engagement with the identified peripheral stakeholders ('fan-in').

Hart and Sharma asserted that established approaches to stakeholder management overemphasise known threats. There is, however, a need 'to manage radical uncertainty by acquiring knowledge from diverse and dispersed heterogeneous stakeholders, many of whom may be adversarial, in order to prevent the surprise emergence of such threats.' (p. 9). The authors note 'swarms of stakeholders self-organiz[ing] in chaotic and unpredictable ways' (p. 8). This language of unexpected and chaotic threats is familiar to those dealing with forest health and biosecurity issues. Although it is focused primarily on human stakeholders organising in new ways (e.g. via the internet), RT seeks to cope with uncertainty and the unexpected in more vital ways. Non-human stakeholders were acknowledged as one category of 'fringe' stakeholders within Hart and Sharma's original paper. However, despite considerable application of RT to non-salient human stakeholders, to date little work has been done to further develop applications to non-human stakeholders. 
'Fanning-out' is fundamentally about expanding the boundaries of stakeholder analysis in ways that were previously considered unnecessary or illegitimate. The goal is to include 'distant voices', to ask the right questions and to improve understanding of problem complexity and scope. Within RT the processes underpinning 'fanning-out' are 'networking from the core to the periphery' and 'putting the last first' (Hart and Sharma 2004). The networking component involves systematically mapping the networks of 'core' stakeholders outwards to generate a considerably broader analysis that is inclusive of stakeholders 'distant' from or 'fringe' to the focal organisation or action. Building upon this, 'putting the last first' means deliberately reversing notions of stakeholder salience by conducting research about, and inviting dialogue with, those stakeholders identified as being powerless or isolated. This begins to expose key individuals (business managers or policy-makers) to radically different perspectives, opening them to 'hearing' these distant voices. A key element of 'putting the last first' is the creation of an 'inventory' of learning opportunities (sites, processes, events).

'Fanning-in' seeks to integrate and reconcile knowledge from identified 'fringe' stakeholders into the existing body of institutional and personal knowledge, which then informs the action taken to manage those stakeholders. Its aim is to generate solutions. The primary element of this process is the generation of 'complex interactions' between managers (policy-makers) and these stakeholders. Hart and Sharma highlight the need for 'deep listening' and 'intense informal conversations' that facilitate the transfer of unwritten or otherwise tacit knowledge and encourage empathy (Hart and Sharma 2004, p14). There is a clear emphasis here on dialogue that goes beyond standard approaches to information gathering. These complex interactions must necessarily take place within the everyday worlds ('operating contexts') of fringe stakeholders, which itself often requires some form of training. These activities remove the learners (managers and policy-makers) from the established logics, routines, and mental models of their normal working lives, with the aim of enabling them to accept challenging information and experiences. The goal of these interactions is to generate potential new practical management strategies or products. The final stage of 'fanning in' involves 'reconciling contradictions' through an ongoing dialogue with fringe stakeholders and the incubation of new perspectives, ideas, and solutions within the organisation. This challenging process requires dedicated time and infrastructure from an organisation, as well as the establishment of diverse committees and/or task forces to develop and test ideas within the original stakeholder contexts from which they emerged. 
What might RT look like in the context of forest health policy? The current impetus to embed stakeholder analysis in environmental policy and management has been applied to forest health (e.g. Dandy et al 2017). Tracing the network of stakeholders outwards from the 'core' to the 'fringe' would not present a significant challenge. Furthermore, methods emanating from scholarly traditions such as animism, multispecies ethnography and 'more-than-human' geography, along with innovative outputs from the creative industries (see, for example, In the Eyes of the Animal ${ }^{3}$ ) offer abundant ways in which to approach an experience of nonhuman stakeholders within forest settings. There is also no shortage of examples of biosecurity practice and 'outbreak' management that policy-makers could use to undertake immersive fieldwork that generates the 'complex interactions' with non-human stakeholders demanded by RT in both 'native' and introduced environments. The final stage of RT, 'reconciling contradictions', would require the establishment of, and allocation of resources to, institutional structures (committees, task forces) within government and other forest health policy-relevant organisations, with the specific remit of taking account of non-human stakes.

\section{Transrational Knowing}

Transrational - or, spiritual - knowing (TK) is a concept articulated by M.J. Barrett (2013a) that draws strongly from Indigenous knowledge systems and is grounded in an animist worldview; her work was the first we encountered which referred to non-humans as 'knowers' (Barrett 2013b, citing Stuckey 2010). Barrett describes how TK is accessed through specific protocols \& practices including dreams, intuition, a 'felt sense', visions, and artistic inspiration; it is most often conveyed through embodied senses. And like other animist ways of knowing, TK 'requires an extended understanding of the self in a world of relations, where not all of them are human' (Barrett 2013a, p. 184): TK includes knowledge obtained through relationships with non-human beings, ancestors, the landscape, and forces of nature. Ultimately, transrational knowing does not exist in opposition to rationality, but beyond it (2013a, p. 184). Whilst there are overlapping characteristics between Indigenous

\footnotetext{
${ }^{3}$ Iteota.com, 'In the Eyes of the Animal', is a $360^{\circ}$ animated, virtual reality 'artistic exploration into the science of seeing' that was created through the use of $360^{\circ}$ cameras and lidar scans. It can be experienced in a live natural environment, where virtual reality headsets enable forest explorers to traverse the animated, realworld, landscape.
} 
Knowledge (IK) and transrational knowing, TK is different because all peoples have access to it.

Barrett states two goals for incorporating TK within socio-ecological decision making processes: “(1) making better decisions for long-term sustainability for all beings, including those who are human and those who are not, and (2) animating processes for decision-making that are inclusive of ways of knowing of all peoples" (2013a, p. 180). To use TK in decisionmaking processes is not to replace scientific knowledge, but to complement and strengthen it, thus bringing us back to Barrett's concept of 'epistemological diversity' (Barrett 2013a, p. 179).

Dyke, et al. (2018) presents a good example of how TK could be introduced to tree health researchers, who could use it to inform policy decision-making. Inspired by the 'more-thanhuman participatory research' carried out by Bastian et al. (2017), the authors brought together an interdisciplinary group of 14 researchers as part of the PuRpOsE project to participate in a two day event called 'In conversation with oak trees' (Dyke et al., 2018, p. 455). Focused on a poorly understood tree disease, Acute Oak Decline (AOD), there were two overarching questions for participants: 'How might we transform our understanding of oak ecosystems and AOD, and what might it mean to research with trees and live with disease?' (p. 458, emphasis original). There were a variety of activities over the two days, but one session in particular called 'Good morning with oak trees' seemed to impact participants. The session consisted of reading a poem and was followed by 'an invitation to spend some time alone with trees and engage senses beyond the visual', which was intended to provide 'an opportunity for intense attention to difference and to develop attunement' (p. 457). Participants reported later that in this session many of them had tried to connect with the perspective of a tree and explored what it might be like to experience life as a tree. An important result from this research was that these different embodied experiences of trees had transformed how participants were interested in trees: their initial interest in facts about the trees was transformed into caring about the trees. Overall, some participants 'found it easier than others to access visceral and embodied experiences', and the authors concluded that 'being in the woods for no purpose other than to experience being with trees also allowed for visceral and embodied experiences that are otherwise usually marginalised in the research 
process' (p. 464). Working within a sometimes uncomfortable multidisciplinary group also seemed to help move participants outside of their disciplinary comfort zone and stretch their professional boundaries to consider new ways of knowing (p. 465).

Applying Radical Transactiveness and Transrational Knowing: 'Nature Constellations' as a Method

'Family constellations' is an experiential group methodology originally developed by Bert Hellinger to reveal the underlying dynamics within families and facilitate healing. The method has evolved to successfully map and work with multiple forms of complex systems, including organisational and political systems. Since the early 2000s, some professional facilitators have focused on applying the method to human/ecological systems, an approach known as 'nature constellations'.

Nature constellations offer us a way to tune into the consciousness of nature, to discover what might support life to thrive in specific situations and in general. Their versatility and accessibility mean they can be applied to any situation where there is a human/OTH [Other Than Human] interface and, with enquirers participating, there is trust in the process and often healing and transformation for both humans and OTHs. (Roussopoulos 2018a, p. 71)

A nature constellation takes place within a group workshop. A person within the group (the enquirer) brings an issue or question regarding a relationship or situation between humans and non-humans. The constellations facilitator then decides, in consultation with the enquirer, which knowers (stakeholders) are relevant to the question and should be represented in the constellation as part of a 'system'. Individuals (reps) are then asked to participate in the constellation by 'representing' one of the selected knowers. The enquirer positions the reps in the workshop space in the form of a 'living map' which 'diagnoses the current state of the human-ecological system' (Roussopoulos 2018b). By 'tuning into' the role they are assuming, the reps embody information about the knower they are standing in for, even though they have no substantive conscious knowledge of that role. Crucially, in many nature 
constellations the facilitator does not tell reps which knower they are representing and the constellation is run 'blind'. This allows reps to 'tune in with OTHs without bringing their own projections' (Roussopoulos 2018a, p. 63).

Instead of being understood as 'role-play', the information accessed by the reps can be described as a form of transrational knowledge in the sense that it is experienced in the form of the emotions, thoughts, and bodily sensations that emerge spontaneously.

the method is ... profoundly interactive and experiential. It arises and evolves through the sensations, feelings and direct knowing of the participants - their internal awareness, their consciousness - and this is where the learning and transformation take place. (Roussopoulos 2018b)

Reps express their embodied knowledge to the group, which provides information about the state of being of the knower they are representing in the constellation. Throughout the constellation, the facilitator asks questions of each rep and can engage the reps in interactions with each other to work out the underlying relationship dynamics. It is also possible to explore how making changes would impact other parts of the system represented in the constellation: 'The aim is to find what would bring improvements to the health and wellbeing of all parts of the system, human and other-than-human' (Roussopoulos 2018b). Solutions emerge as part of this process - sometimes those which have not been previously considered - which are co-created by all present. As well as nature constellations providing information and generating solutions, "the process of "representing" parts of nature, of stepping into another's paws... or roots... can be powerfully transformative for people' (Roussopoulos 2018b).

It is important to note that accepting the actuality of knowledge generated by nature constellations, particularly the notion of experiential knowledge embodied by humans as somehow 'representative' of non-human experience, presents a significant challenge to individuals and institutions immersed in 'western' science. This is at least in part because the mechanism via which knowledge is generated is unclear to 'scientific' observation and 
explanation. In putting forward nature constellations as a potential method our goal is not to offer a defence of it as a method per se, but simply to raise the possibility of the use of embodied knowledge to open-up forest health policy making to take non-human stakes more seriously.

Within the context of policy decision-making in tree health, nature constellations could be used as a method in many ways, such as for exploring a particular tree pathogen or 'pest', deepening understanding of a struggling forest ecosystem, or gaining insight into the current tree health 'crisis' more broadly. While nature constellations can be done spontaneously, for the best results with complex scenarios or research-oriented questions, a three stage process may be recommended: preparation, nature constellation(s), integration (Roussopoulos, pers. comm. 2020). The preparation stage enables the facilitator to plan an appropriate event, sketching out the constellation(s) required to address the core questions and identifying, with the enquirer(s), whom to invite. This usually clarifies which stakeholders should be represented, but Radical Transactiveness could also be used to explore which stakeholders are most relevant, from the 'core' to the 'fringe', with particular attention being paid to the non-human stakeholders who are not usually included in tree health research.

If investigating a particular 'outbreak' in a specific location, the reps in the constellation would include, at least: the trees, the 'pest', humans (possibly representing 'humankind', or specific human groups like Indigenous peoples, or special interest organisations), the land in affected areas, and other non-human beings affected by the proposed management method. There could be a rep for a possible management solution (biological control using another species for example), something which is often done within organisational constellations. The event could involve a few people for a few hours, or a larger group over a few days to explore questions in depth. Capturing the data can be done in a number of ways, such as audio or video recordings during the event and interviews with reps and enquirers afterwards. In the integration stage, the facilitator and enquirers would review the material to identify the key lessons and appropriate next steps. The outcomes from this process, combined with information from more traditional research methods such as data about similar outbreaks, would provide a more complete picture about how to proceed in the situation. 


\section{Discussion and conclusions}

In this paper we have sought to set out a framework for the eclosion of forest and tree health policy. We propose a transformation in this field such that the impacts on, and consequences of, forest health policy and practice for non-humans are taken seriously. We have demonstrated that whilst undoubtedly some fundamental shifts in practice and approach are required, a number of coherent and nested concepts and methods are available that can facilitate the required transformation.

The concept of stakeholdership provides a firm foundation on which to construct this framework, although there is still work to be done to find the most appropriate terminology and epistemology for including non-human stakeholders. Their inclusion needs to be meaningful to policy makers and internally coherent enough to allow judgements to be made on who is a stakeholder and who is not. However, it is clear that the broad character and type of stake that can be held by non-humans can be comprehensibly described, and stakeholdership can consequently be considered an appropriate framework from a socioecological policy perspective.

A focus on stakeholdership is also complementary to parallel approaches that seek to emancipate non-humans within policy processes and other arenas. In particular, it provides a framework that is in some ways less demanding than alternatives such as the 'rights of nature' discourse and practice that is well-developed within ethical and legal circles (e.g. Burdon, 2014; Boyd, 2017) and has recently been picked up on by those in the ecological sciences (e.g. Chapron et al . 2019). Rights-based discourses often deal directly with legal structures and obligations. Stakeholdership enables substantive reflection on the previously ignored consequences of forest health policy and practice for non-humans, and also offers a more flexible framework for reconciling problematic intra-human relations than other contemporary approaches which reinforce and perpetuate exclusively western legal epistemologies at the expense of indigenous philosophies, such as some reconciliation processes (see Murdock 2018). 
A new, inclusive conceptualisation of 'stakeholder' allows us to envision approaches that can provide deeper knowledge of the perspectives of non-humans. We have demonstrated there are a number of methods emanating from a wide range of disciplines that can be utilised to appropriately 'listen to' non-human voices in decision- and policy-making processes. These are not mutually exclusive, but rather could be nested within one another to facilitate nonhuman voices being heard increasingly loudly and clearly.

To what extent might we expect the transformation and approaches we describe to be implemented in contemporary policy and practice? What are the most likely substantive barriers to change and the adoption of part or all of the proposed approaches? Whilst there would certainly be resource implications, such as small-scale financial costs and a more substantive investment of time, the most profound barrier is likely to be openness amongst policy-makers and other human stakeholders; openness not only to new terminologies and practices, but also to learning new epistemologies. These generate forms of knowledge (or 'evidence') that lie beyond those usually considered legitimate within stakeholder engagement processes. Getting a group of policy-makers to undertake a nature constellations process is one challenge, but enabling the integration and acceptance of the insights generated by that process is another. Openly sharing transrational knowledge can be risky, even for those who are respected players within policy decision-making environments. Within a system that widely considers non-human beings to be objects, admitting that one has been in conversation with such Others could result in social stigma and professional penalties. In short, the eclosion of stakeholdership also demands epistemological and professional eclosion.

In the case of 'In conversation with oak trees' (above), the long term impact on researchers' perspectives is unknown. Did their newfound caring about the trees lose its power after they had integrated their personal experiences with the trees into their more conventional working life? It is possible that multiple opportunities for researchers and policy makers to engage with more-than-human participatory research would allow them to become more 'porous' (Barrett 2013a) to other ways of knowing and result in lasting change. Although recent attention to scholarly fields like ‘the new animism' (see Harvey 2013) and human-animal studies has made academia - the social sciences and humanities, in particular - a more 
receptive place for ideas about the personhood of non-human beings and unorthodox methods of communication with them, this openness has been slow to filter through to policy actors.

The research and practice surrounding each of the approaches we have described consistently highlights the need for this openness. Proponents of transrational knowing refer to the need for 'an extended understanding of the self in a world of relations' (Barrett 2013a, p. 184), whilst radical transactiveness demands the unburdened and deliberate crossing of established boundaries of stakeholdership. Even simple proxy representation requires proactively offering a 'seat at the table' to non-traditional actors. There is also consistency in identifying the need for trained or otherwise empowered individuals to be in place within these processes to facilitate and promote openness. As noted above, time is another important resource, not only to develop, test and implement new approaches but also to enable the emergence of openness. In reference to transrational knowing, Barrett recites Nobel Prize winner Barbara McClintock's perspective that emanated from her work on gene transposition: “Over and over again she tells us one must have the time to look, the patience to hear 'what the material has to say to you', the openness to 'let it come to you'.' (Barrett 2013, p. 186, citing Keller). Exposure to and experience of 'nature' (i.e. non-humans) is another facilitator of openness identified by practitioners of the varied approaches we describe here.

Conceptualising and relating to other beings as 'knowers' is a fundamentally animist perspective, 'animists' being 'people who recognise that the world is full of persons, only some of whom are human, and that life is always lived in relationship with others' (Harvey 2006, p. xix). Animism has been identified with Indigenous cultures whose ways of knowing have historically been ignored and devalued by Western epistemology. By widening the scope of environmental management decision making and policy to include the voices of non-human beings, we are also validating the voices of 'Othered' human communities. Through the creation and establishment of speciesist and gendered dualisms that enable and legitimate the exploitation and degradation of less powerful 'others' (Plumwood, 2002), and in combination with a worldview that forces humans and non-humans into a hierarchy, Western scientific approaches have created the complex environmental problems we all face on Earth in the present. Fundamentally, encouraging 'epistemological diversity' has the 
potential to result in policy that is profoundly intersectional and benefits all knowers (Barrett 2013a, p. 179).

Contemporary forest and tree health policy, and its related biosecurity practices, have enormous consequences for non-humans and humans alike. Consequences for non-humans are rarely, if ever, featured in related decision-making processes. Recognition of the Anthropocene serves to highlight, once again, the nature and scale of these anthropogenic impacts. Long-standing calls from within environmental ethics, multi-species ethnography and other fields of enquiry, as well as ever-increasing evidence for non-human agency, demand the emergence and hatching of new and more inclusive processes so as to take these consequences seriously.

In this paper we have sought to demonstrate that such an 'eclosion' of forest and tree health is feasible, and the greatest barriers are likely to be vested epistemological and political interests, rather than the availability of effective processes or rigorous conceptual tools. An approach based on the concept of stakeholdership offers a flexible and pragmatic way forward: one which is meaningful but does not immediately or necessarily place potentially dramatic demands on policy-makers. This can underpin an inclusive and adaptive approach that allows careful consideration of the interests and influence of non-humans.

\section{ACKNOWLEDGEMENTS}

This paper has been long in development with aspects being presented at the 2015 and 2016 annual conferences of the Royal Geographical Society, and to a number of academic audiences over time. The authors are grateful for comments and suggestions received from attendees during those events. We are also grateful to two anonymous reviewers who provided further thoughtful and useful remarks.

\section{REFERENCES}


Amo, L., J.J. Jansen, N.M. van Dam, M. Dicke and M.E. Visser. 2013. 'Birds exploit herbivore-induced plant volatiles to locate herbivorous prey'. Ecology Letters 16: 1348-1355.

Bastian M., O. Jones, N. Moore and E. Roe (eds.). 2017. Participatory Research in Morethan-Human Worlds. Abingdon: Routledge.

Barrett, M.J. 2013a. 'Enabling hybrid space: epistemological diversity in socio-ecological problem-solving'. Policy Science 46: 179-197.

Barrett, M.J. 2013b. 'Researching through porosity: an animist research methodology', in G. Harvey (ed.) The Handbook of Contemporary Animism, Durham, UK: Acumen Publishing Inc.

Boyd, D. R. 2017. The rights of nature: A legal revolution that could save the world. Toronto, ON: ECW Press.

Brasier, C. 2008. 'The biosecurity threat to the UK and global environment from international trade in plants'. Plant Pathology 57: 792-808.

Buller, H. 2013. 'Introducing Aliens, Reintroducing Natives: A conflict of interest for biosecurity?' in A. Dobson, K. Barker and S. Taylor (eds.) Biosecurity: The socio-politics of invasive species and infectious diseases. Routledge: London.

Burdon, P. 2010. 'The Rights of Nature: Reconsidered'. Australian Humanities Review 49: 69-89.

Carroll, A.L., S.W. Taylor, J. Regniere and L. Safranyik. 2003. 'Effect of climate change on range expansion by the mountain pine beetle in British Columbia'. The Bark Beetles, Fuels, 
and Fire Bibliography. Paper 195. https://digitalcommons.usu.edu/barkbeetles/195, (accessed 7 November 2018).

Castello, J. D. and S. A. Teale. 2011. Forest Health: An Integrated Perspective. Cambridge: Cambridge University Press.

Chapron, G., Y. Epstein and J.V. López-Bao. 2019. 'A rights revolution for nature'. Science, 363: 1392-1393.

Dandy, N., E. Porth and R. Hague. 2018. 'Environmental Ethics of Forest Health: Alternative stories of Asian longhorn beetle management in the UK'. In: Urquhart J, M. Marzano and C. Potter (eds.) The Human Dimensions of Forest and Tree Health: Global Perspectives, Palgrave Macmillan, pp 419-444.

Dandy, N., M. Marzano, E.F. Porth, J. Urquhart, and C. Potter. 2017. 'Who has a stake in ash dieback? A conceptual framework for the identification and categorisation of tree health stakeholders', in R. Vasaitis and R. Enderle (Eds.) Dieback of European Ash (Fraxinus spp.): Consequences and Guidelines for Sustainable Management, Swedish University of Agricultural Sciences, pp 15-26.

Davidson, I. (2017, March 15). 'Whanganui River given legal status of a person under unique Treaty of Waitangi settlement'. New Zealand Herald.

Defra. 2011. Action Plan for tree health and plant biosecurity. Defra and Forestry Commission. October 2011.

Draney, M.L. 1997. 'Ethical Obligations Toward Insect Pests'. Ethics and the Environment 2: 5-23. 
Driscoll, C. and M. Starik (2004) 'The Primordial Stakeholder: Advancing the Conceptual Consideration of Stakeholder Status for the Natural Environment'. Journal of Business Ethics 49: $55-73$

Dyke, A., H. Geoghegan and A. de Bruin. 2018. 'Towards a More-Than-Human Approach to Tree Health', in J. Urquhart, M. Marzano, and C. Potter (Eds.) The Human Dimensions of Forest \& Tree Health: Global Perspectives, Palgrave-Macmillan, pp. 445-470.

Evans H.F. and N.J. Fielding. 1994. 'Integrated management of Dendroctonus micans in the UK'. Forest Ecology and Management 65: 17-30.

FAO. 2015. Invasive species: impacts on forests and forestry. Available at www.fao.org/forestry/aliens (accessed 09/04/2016)

FAO. 2016. ISPM 5 Glossary of phytosanitary terms. Available at: http://www.fao.org/fileadmin/user_upload/faoterm/PDF/ISPM_05_2016_En_2017-0525 PostCPM12_InkAm.pdf (accessed 16 January 2020)

Frawley, J. and I. McCalman. 2014. Rethinking Invasion Ecologies from the Environmental Humanities. Earthscan: London

Freeman, R.E. 1984. Strategic Management: a Stakeholder Approach. Basic Books, New York.

Haack, R.A., F. Hérard, J. Sun and J.J. Turgeon. 2010 'Managing Invasive Populations of Asian Longhorned Beetle and Citrus Longhorned Beetle: A Worldwide Perspective', Annual Review of Entomology 55: 521-546. 
Hart, S.L. and S. Sharma. 2004. 'Engaging fringe stakeholders for competitive imagination'. Academy of Management Perspectives 18: 7-18.

Harvey, G. (Ed.). 2013. The Handbook of Contemporary Animism. Acumen Publishing Limited: Durham.

Harvey, G. 2006. Animism: Respecting the Living World. Columbia University Press: New York.

Human Animal Research Network Editorial Collective. 2015. Animals in the Anthropocene: Critical perspectives on non-human futures. Sydney: Sydney University Press.

Keller, E. 1983. A feeling for the organism: The life and work of Barbara McClintock. New York: W.H. Freeman and Company.

Lambert S., N. Waipara, A. Black, M. Mark-Shadbolt and W. Wood. 2018. 'Indigenous Biosecurity: Māori Responses to Kauri Dieback and Myrtle Rust in Aotearoa New Zealand'. In: Urquhart J., M. Marzano and C. Potter (eds) The Human Dimensions of Forest and Tree Health: Global Perspectives. Palgrave Macmillan, pp 109-137.

Lindell C.A., D.G. McCullough, D. Cappaert, N.M Apostolou and M.B Roth. 2008. 'Factors Influencing Woodpecker Predation on Emerald Ash Borer'. The American Midland Naturalist 159:434-444.

Lockwood, J.A. 1987. 'The moral standing of insects and the ethics of extinction\#. Florida Entomologist 70: 70-89

Lockwood, J.A. 1988. 'Not to harm a fly: Our ethical obligations to insects'. Between the Species 4: 204-211. 
Lorimer, J. 2010. 'Elephants as companion species: the lively biogeographies of Asian elephant conservation in Sri Lanka'. Transactions of the Institute of British Geographers 35: 491-506.

Mack, R.N., D. Simberloff, D., W.M. Lonsdale, H. Evans, M. Clout and F.A. Bazzaz. 2000. 'Biotic invasions: Causes, epidemiology, global consequences, and control'. Ecological Applications 10: 689-710.

Murdock, E.G. 2018. 'Unsettling Reconciliation: Decolonial Methods for Transforming Social-Ecological Systems'. Environmental Values 27: 513-533.

O’Donnell E.L. 2018. 'At the Intersection of the Sacred and the Legal: Rights for Nature in Uttarakhand, India'. Journal of Environmental Law 30: 135-144.

Perry, D. A., R. Oren, S.C. Hart. 2008. Forest Ecosystems. (2 ${ }^{\text {nd }}$ Edition) John Hopkins University Press.

Phillips, R.A. and J. Reichart. 2000. 'The Environment as a Stakeholder? A Fairness-Based Approach'. Journal of Business Ethics 23: 185-197

Plumwood, V. 2002. Environmental Culture: The Ecological Crisis of Reason. New York: Routledge.

Reed, M. S., A. Graves, N. Dandy, H. Posthumus, K. Hubacek, J. Morris, C. Prell, C.H. Quinn and L.C. Stringer (2009) 'Who's in and why? A typology of stakeholder analysis methods for natural resource management', Journal of Environmental Management 90: 193349. 
Regan, T. 1981. 'The nature and possibility of an environmental ethic', Environmental Ethics, 3: 19-34.

Romero, J and J.S. Dryzek. 2020. 'Grounding Ecological Democracy: Semiotics and the Communicative Networks of Nature'. Environmental Values forthcoming.

Roques, A. 2010. 'Alien forest insects in a warmer world and a globalised economy: Impacts of changes in trade, tourism and climate on forest biosecurity'. New Zealand Journal of Forest Science 40: S77-94.

Roussopoulos, M. 2018a. 'Nature Constellations: Exploring our Profound Interconnectedness with All Life'. The Knowing Field: International Constellations Journal. 31: 61-71.

Roussopoulos, M. 2018b. 'Forgotten Connections: Nature Constellations'. Available at: http://www.forgottenconnections.org/nature-constellations/ (accessed 16 April 2018).

Rutherford, S. 2018. 'The Anthropocene's animal? Coywolves as feral cotravelers'. Environment and Planning E. 1: 206-223.

Sage, D., A. Dainty, K. Tryggestad, L. Justesen and J. Mouritsen. 2014. 'Building with wildlife: project geographies and cosmopolitics in infrastructure construction'. Construction Management and Economics 32: 773-786.

SBS News. 2020. 'Australia's biodiversity has taken a massive hit during the recent bushfires'. Available at:

https://www.sbs.com.au/news/the-australian-bushfires-have-killed-an-estimated-1-25-billionanimals (accessed 16 January 2020). 
Starik, M. 1995. 'Should trees have managerial standing? Toward stakeholder status for nonhuman nature'. Journal of Business Ethics. 14: 207-217.

Steffen, W., P.J., Crutzen and J.R. McNeill .2007. 'The Anthropocene: Are Humans Now Overwhelming the Great Forces of Nature?'. Ambio 36: 614-621.

Stuckey, P. 201). 'Being Known by a Birch Tree: Animist Refigurings of Western Epistemology'. Journal for the Study of Religion, Nature and Culture, 4: 182-205.

Tryggestad, K., L. Justesen and J. Mouritsen. 2013. 'Project temporalities: how frogs can become stakeholders'. International Journal of Managing Projects in Business 6: 69 - 87.

Waddock, S.A. 2011. 'We Are All Stakeholders of Gaia: A Normative Perspective on Stakeholder Thinking'. Organization \& Environment 24: 192-212

Webber, J. 2010. 'Pest risk analysis and invasion pathways for plant pathogens'. New Zealand Journal of Forest Science 40: S45-56. 